\title{
Sensorless Vector Controlled Multilevel Inverter Fed BLDC Motor
}

\author{
Mustafa B. Abdulmelik \\ M.Sc. Student \\ Department of Electrical Engineering \\ Almustansiriya University
}

\author{
Turki K. Hassan, PhD \\ Supervisor \\ Department of Electrical Engineering \\ Almustansiriya University
}

\begin{abstract}
BLDC motors are mostly known to be driven by trapezoidal control due to its simple implementation, but this type of control results in pulsating torque ripple which is unwanted in high performance drives. In this paper, vector control is combined with a five-level inverter to minimize the torque ripple of BLDC motor in sensorless operation as well as reducing the total harmonic distortion in the voltage and current waveforms. The MATLAB/Simulink environment is used to simulate and verify the proposed method.
\end{abstract}

\section{Keywords}

BLDC motor, multilevel inverter, sensorless control, torque ripple reduction, vector control.

\section{INTRODUCTION}

Brushless DC (BLDC) motors are becoming very popular in both commercial and industrial applications due to its many merits such as its high efficiency, high power density, low maintenance and lower electromagnetic interference (EMI).

These motors have the same structure as the brushed motors; they consist mainly of stator with windings and a rotor that contains permanent magnets instead of windings. The rotor is rotated by attraction between the electromagnets formed in the stator and the permanent magnets.

The conventional control for BLDC motors is six-step or trapezoidal control; this control energizes two phases at a time and leave the third phase floating; then, a rotating flux vector is formed in the stator that drags the rotor with it with appropriate switching signals relative to the rotor position. This control is very simple and is easy to implement; however, high pulsating torque ripple is associated with this type of control A way to improve the performance of BLDC drives is to drive the motor with vector control. This control is mostly used with PMSM drives and it can also be used with BLDC motors and this can minimize the torque ripple and improve the dynamic response of the drive.

Shucheng [1] proposed using Sinusoidal PWM with BLDC motor to reduce the torque ripple. The results shows reduction of about $50 \%$ of the torque ripple compared with the six-step control but the dynamic performance of the drive was not very efficient because of the absence of the current control loop and there is considerable harmonic components in current waveform.

Rau [2],Sensorless vector control is applied to a BLDC motor to achieve better efficiency and better dynamic response of the drive, the results showed improvement performance over sixstep control and a fast dynamic response. However, the torque and speed had a large ripple that should be minimized.
Multilevel inverters are being used widely in medium and high voltage motors due to its many advantages over the twolevel inverter such as the reduction in the harmonic distortion, lower $\mathrm{dv} / \mathrm{dt}$ which reduces the stress over switching devices, lower distortion of input current and the ability of operation at high and low switching frequencies.

Previous work has been done regarding the use of multilevel inverter with BLDC motors in [3-5] and results showed a lot of improvement over two-level inverter to lower the total harmonic distortion of the output voltage waveform; however, current distortion and torque transient response wasn't addressed by the authors .

The sensorless control of BLDC motor has been around for a while and it gives several advantages over the use of sensors that includes lower cost especially with the use of vector control where high resolution is required and the sensors become expensive, less space, improved reliability and the ability to work under high pressure and high temperature environments.

Many methods were proposed for position and speed estimation for BLDC motors; most of them are based on the detection of the back electromotive force (emf) of the floating phase [6-8]. These methods are simple and doesn't require complex computations; however, they are less efficient at low speeds because the signal of the back emf becomes low and distorted.

In this paper, a five-level inverter is used with vector control to achieve reduced torque ripple and good speed response for sensorless operation of BLDC motors. The method is tested and verified using MATLAB/Simulink environment.

\section{BLDC MOTOR MODELING}

BLDC motor works with the same principle as a synchronous motor; when the stator windings are energized with alternating three phase currents, a rotating magnetic motive force (mmf) is established; with a proper switching of the stator currents, this mmf drags the rotor by the force of attraction and the rotor rotates with the same frequency as the rotating field. The modeling of the motor is set by the following equations [9]:

$$
\begin{aligned}
& v_{a}=e_{a}+i_{a} R_{s}+L_{s}\left(d i_{a} / d t\right) \\
& v_{b}=e_{b}+i_{b} R_{s}+L_{s}\left(d i_{b} / d t\right) \\
& v_{c}=e_{c}+i_{c} R_{s}+L_{s}\left(d i_{c} / d t\right)
\end{aligned}
$$

Where $\mathrm{v}_{\mathrm{a}}, \mathrm{v}_{\mathrm{b}}$ and $\mathrm{v}_{\mathrm{c}}$ are the Phase voltages in volts, $\mathrm{e}_{\mathrm{a}}, \mathrm{e}_{\mathrm{b}}$ and $\mathrm{e}_{\mathrm{c}}$ are the back emf of each phase in volts, $\mathrm{i}_{\mathrm{a}}, \mathrm{i}_{\mathrm{b}}$ and $\mathrm{i}_{\mathrm{c}}$ are the phase currents in ampere, $R_{S}$ is the stator resistance in oh$\mathrm{m}$ and $\mathrm{L}_{\mathrm{S}}$ is the stator self-inductance in hennery. 
$e_{a}=K_{e} . f(\phi) . \omega(t)$

$e_{b}=K_{e} \cdot f(\phi-2 \pi / 3) \cdot \omega(t)$

$e_{c}=K_{e} \cdot f(\phi+2 \pi / 3) \cdot \omega(t)$

Where $\phi$ is the rotor position in radians, $\mathbf{K}_{\mathbf{e}}$ is the back emf constant in $\mathrm{V} / \mathrm{rad} / \mathrm{sec}, \omega$ is the rotor speed in $\mathrm{rad} / \mathrm{sec}$ and $\mathbf{f}(\phi)$ is a function changes with the rotor position.

The developed electromagnetic torque is given by the equations:

$\mathrm{T}_{\mathrm{e}}=\left(\mathrm{e}_{\mathrm{a}} \mathrm{i}_{\mathrm{a}}+\mathrm{e}_{\mathrm{b}} \mathrm{i}_{\mathrm{b}}+\mathrm{e}_{\mathrm{c}} \mathrm{i}_{\mathrm{c}}\right) / \omega$

$\mathrm{T}_{\mathrm{e}}=\mathrm{K}_{\mathrm{t}} \cdot \mathrm{I}_{\mathrm{q}}$

Where $\mathbf{T}_{\mathbf{e}}$ is the electromagnetic torque in $\mathrm{N} \cdot \mathrm{m}, \mathbf{K}_{\mathbf{t}}$ is the torque constant in N.m/A and Iq is the quadrature current component in Amperes. The dynamic equation of the motor is giving by:

$\mathrm{T}_{\mathrm{e}}-\mathrm{T}_{\mathrm{L}}=\mathrm{B} \cdot \omega+\mathrm{J}(\mathrm{d} \omega / \mathrm{dt})$

Where $\mathrm{T}_{\mathrm{L}}$ is the applied load torque in N.m, B is the friction coefficient in N.m.s and $\mathrm{J}$ is the moment of inertia of the motor in kg. $\mathrm{m}^{2}$.

In order to achieve maximum torque, the angle between the stator magnetic field and the rotor magnetic field should be 90 degrees according to the equation:

$\mathrm{T}_{\mathrm{e}}=\mathrm{F}_{\mathrm{s}} \times \mathrm{F}_{\mathrm{r}}$

Where $F_{s}$ is the force of the stator magnetic field and $F_{r}$ is the force of the rotor.

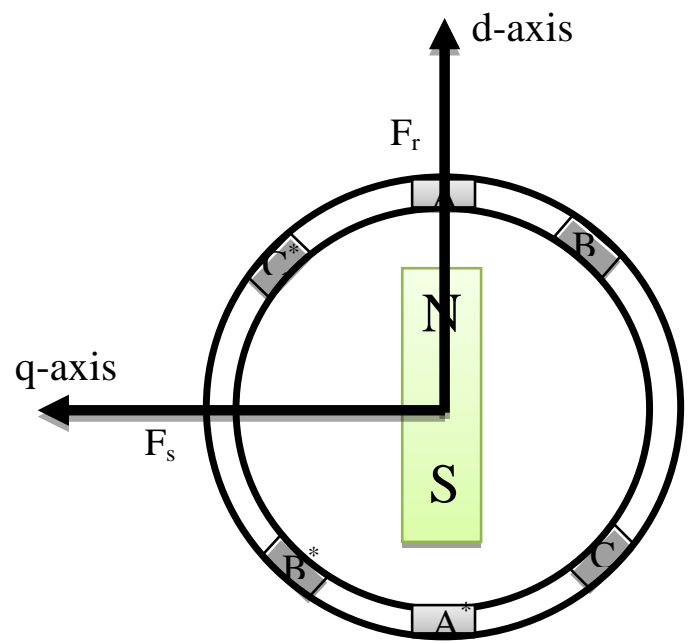

Figure 1 BLDC Motor with Vector Control applied

With vector control applied to the motor, the angle between the two fields remains fixed at 90 degrees thus the dynamic response is greatly improved.

\section{MULTILEVEL INVERTER}

In order to get lower harmonic distortion in the output waveform, multilevel inverters can be used to synthesize the voltage into a number of levels. The higher is the number of levels, the closer is the output voltage waveform to a sinusoidal shape and therefore reducing the harmonic distortion [10].
There are a number of multilevel inverter topologies, the most popular are the cascaded $\mathrm{H}$-bridge (CHB), neutral pointclamped (NPC) and the flying capacitor.

The NPC and flying capacitor topologies have a problem of voltage unbalance which can be more severe with over three levels. The CHB topology doesn't have this problem but have the disadvantage of the need of isolated DC sources.

The CHB method consists of a series connected H-bridges, each bridge has one DC source. The number of H-bridges depends on the number of levels generated by the multilevel inverter according to the following equation [11]:

$\mathrm{M}=(\mathrm{N}-1) / 2$

Where $\mathrm{M}$ is the number of $\mathrm{H}$-bridges and $\mathrm{N}$ is the number of levels.

Sinusoidal pulse width modulation (SPWM) is one of the most popular modulation techniques in multilevel inverter modulation. It is based on a comparison between a modulating sine wave signal and a number of triangular carrier signals given by $\mathrm{N}-1$.

There are different techniques for SPWM, mainly the level shifted modulation and phase shifted modulation [12]. In this paper, the level shifted modulation with phase disposition is used.

\section{SPEED AND POSTION ESTIMATION}

The speed and position are estimated using the rotor flux vectors which are found from the motor's equations as follows [12]:

$$
\begin{aligned}
& \psi_{\alpha s}=\int\left(v_{\alpha}-\mathrm{i}_{\alpha} \mathrm{R}_{\mathrm{s}}-\omega_{\mathrm{o}} \psi_{\alpha s}\right) \mathrm{dt} \\
& \psi_{\beta s}=\int\left(\mathrm{v}_{\beta}-\mathrm{i}_{\beta} \mathrm{R}_{\mathrm{s}}-\omega_{\mathrm{o}} \psi_{\beta s}\right) \mathrm{dt}
\end{aligned}
$$

Where $\mathrm{v}_{\alpha}, \mathrm{v}_{\beta}, \mathrm{i}_{\alpha}$ and $\mathrm{i}_{\beta}$ are the voltages and currents in the $\alpha$ and $\beta$ coordinates found by Clarke's transformation, $\psi_{\alpha s}$ and $\psi_{\beta s}$ are the stator fluxes in wb and $\omega_{0}$ is the cutoff frequency of the lowpass filter that is used to eliminate the dc offset caused by the integration. The cutoff frequency is set experimentally to $20 \mathrm{rad} / \mathrm{s}$. The rotor flux vectors are then found by:

$\psi_{\mathrm{PM} \alpha}=\psi_{\alpha \mathrm{s}}-\mathrm{L}_{\mathrm{s}} \mathrm{i}_{\alpha}$
$\psi_{\mathrm{PM} \beta}=\psi_{\beta \mathrm{s}}-\mathrm{L}_{\mathrm{s}} \mathrm{i}_{\beta}$

Where $\psi_{\mathrm{PM} \alpha}$ and $\psi_{\mathrm{PM} \beta}$ are the rotor fluxes in wb. Then, the speed and position are extracted from a phase locked loop (PLL) structure as follows:

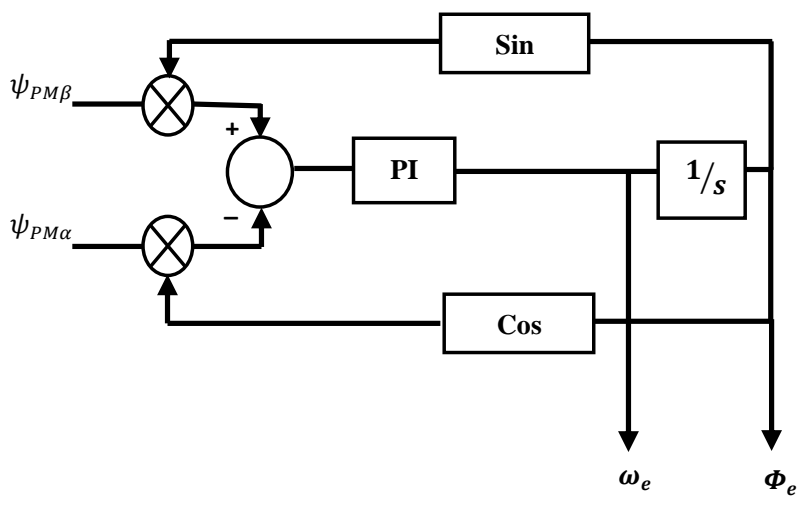

Figure 2 PLL structure 
Where $\omega_{\mathrm{e}}$ and $\Phi_{\mathrm{e}}$ are the electrical speed and electrical position of the rotor respectively. PLL is a method used to detect the phase and frequency of a signal. The above structure is a quadrature-PLL (Q-PLL) used when the inputs are two orthogonal signals [13].

\section{PROPOSED METHOD}

The proposed scheme is shown in figure 3. The BLDC motor is fed from a five-level cascaded $\mathrm{H}$-bridge inverter; the inverter gate signals are provided by level- shifted phase disposition SPWM. The $I_{d}$ and $I_{q}$ currents are obtained from transforming the three phase currents by Clarke and Park transformations and the two currents are controlled by proportional-integral (PI) controllers. The speed and position are obtained from the speed estimator block; the estimated speed is first filtered by a low pass filter (LPF) and is then compared with the reference speed. The estimated position is used in the Park and Park Inverse transformations. The output of the currents controllers are transformed from $\mathrm{d}-\mathrm{q}$ coordinates to $a-b-c$ coordinates by Clarke inverse and Park inverse transformations; these signals represent the reference per unit voltages which are given to the SPWM block to be compared with the carrier signals to generate the gate signals for the multilevel inverter.

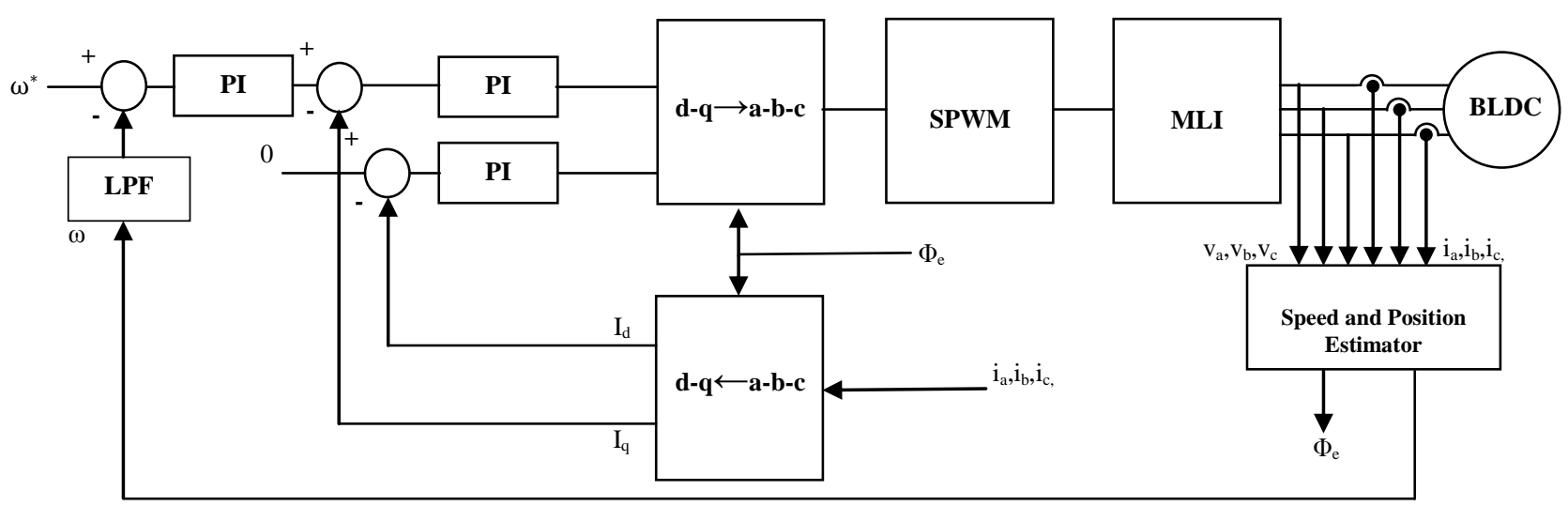

Figure.3 Block diagram of the proposed method

\section{SIMULATION RESULTS AND DISCUSSION}

The simulation was built using MATLAB/Simulink program.

The motor specifications are listed below:

Table 1. Motor specifications

\begin{tabular}{|c|c|}
\hline Rated Voltage & $500 \mathrm{v}$ \\
\hline Rated Speed & $3000 \mathrm{rpm}$ \\
\hline Stator Resistance & $2.875 \Omega$ \\
\hline Stator Inductance & $8.5 \mathrm{mH}$ \\
\hline Number of Poles & 8 \\
\hline Moment of Inertia & $0.8 * 10-3 \mathrm{Kg} . \mathrm{m} 2$ \\
\hline Friction Coefficient & $1 \mathrm{mNm} . \mathrm{s}$ \\
\hline Rated Torque & $3 \mathrm{Nm}$ \\
\hline Voltage Constant & $0.146 \mathrm{v} / \mathrm{rpm}$ \\
\hline Torque Constant & $1.4 \mathrm{Nm} / \mathrm{A}$ \\
\hline
\end{tabular}

The following figures show the obtained simulation results:
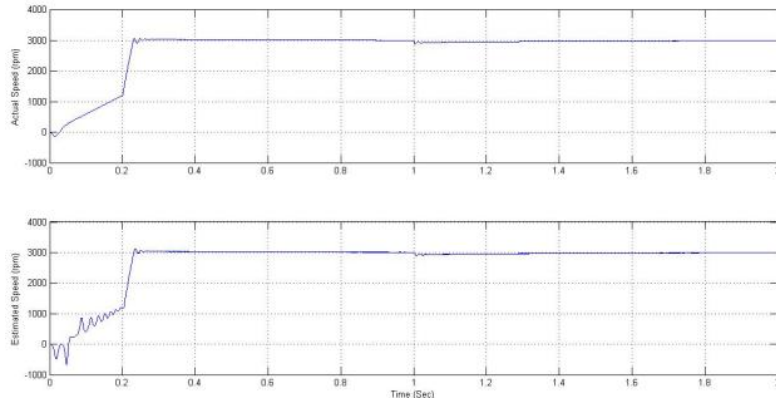

Figure.4 Actual and estimated rotor speed

Since the rotor initial position is not known, the motor is first driven in open-loop mode by $\mathrm{v} / \mathrm{f}$ ramp until the motor picks up the speed and the control is switched to sensorless mode. At time 1 second, a 3 N.m load is applied to the motor; the speed drops of about $70 \mathrm{rpm}$ and then returns after $0.7 \mathrm{sec}$ to the reference speed.

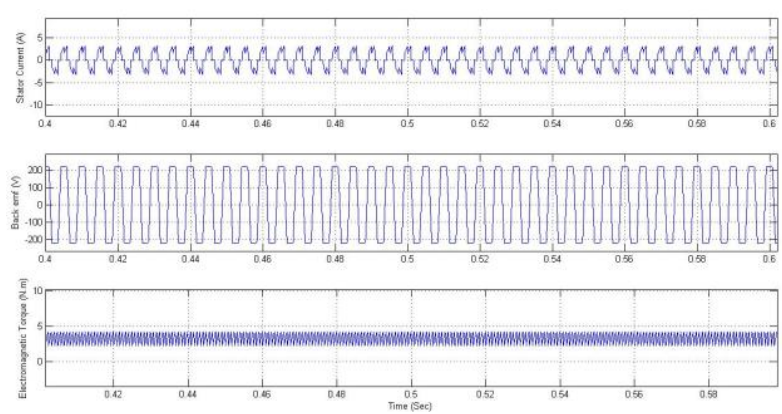

Figure.5 Current, back emf and electromagnetic torque of trapezoidal control at rated speed 

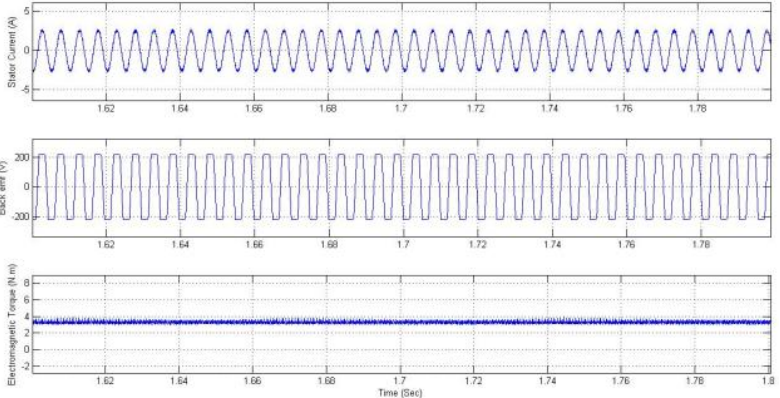

Figure.6 Current, back emf and electromagnetic torque for the proposed method
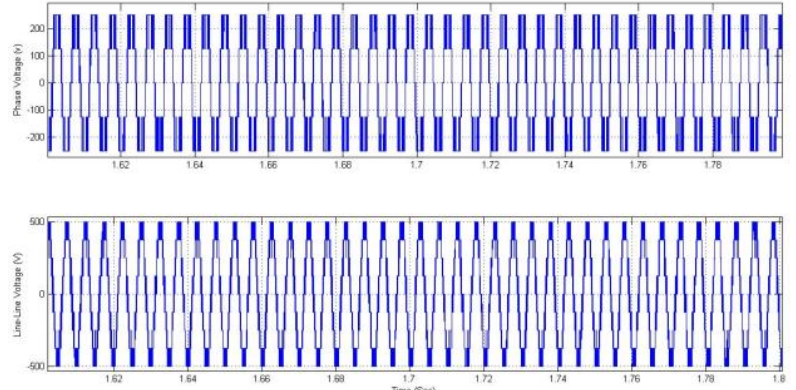

Figure. 7 Five-level phase voltage and nine-level line-line voltage at rated speed

From the figures 5-7 it is seen that the current of the proposed method is close to a sinusoidal shape with a total harmonics distortion (THD) of less than 5\% which is a reduction of more than $600 \%$ of the current THD in the trapezoidal control. The back emf is shown to be trapezoidal in shape in both controls although the current shape is different and that is because its shape mainly depends on how the windings are distributed in the stator. The torque as shown in the proposed method have a ripple percentage of about $20 \%$ at rated speed which is a reduction of about $70 \%$ compared with the traditional trapezoidal control.
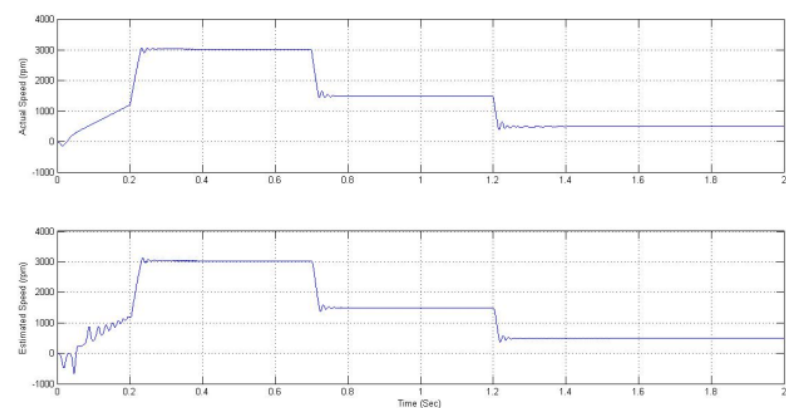

Figure.8 Dynamic performance of the motor

Figure. 8 shows the dynamic performance of the motor when the speed is changed from $3000 \mathrm{rpm}$ to $1500 \mathrm{rpm}$ and then to $500 \mathrm{rpm}$. The speed response is robust and is shown to track the reference speed efficiently even at low speeds with a little overshoot of 0.02 and steady state error of about $0.26 \%$ and speed ripple of $0.5 \mathrm{rpm}$ at high and medium speeds and about $4 \mathrm{rpm}$ at low speeds.
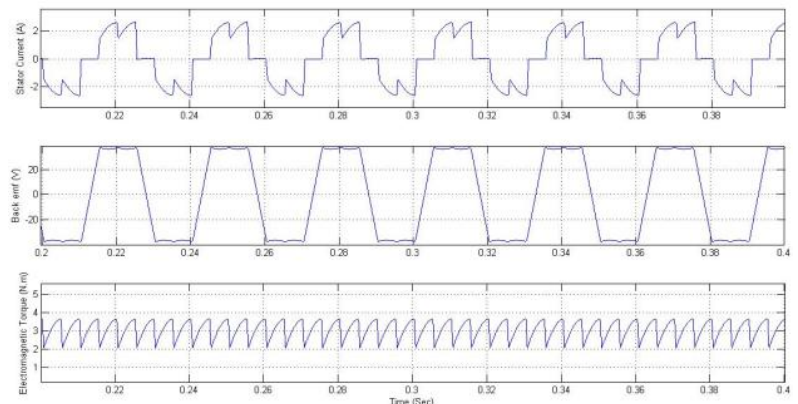

Figure.9 Current,back emf and electromagnetic torque of trapezoidal control at $500 \mathrm{rpm}$
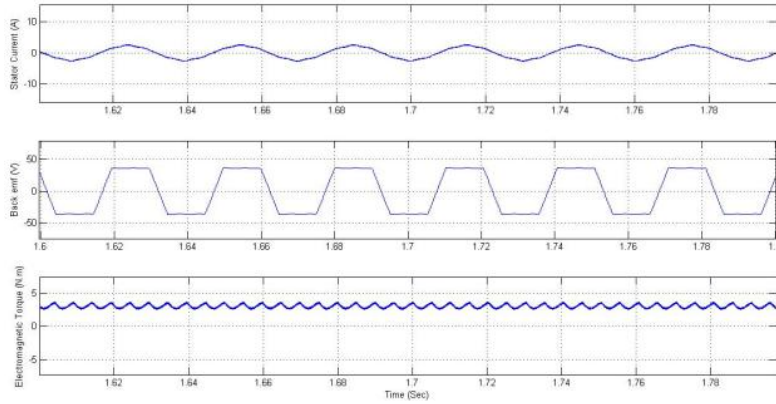

Figure.10 Current, back emf and electromagnetic torque of the proposed method at $500 \mathrm{rpm}$

Figures 9,10 show the torque ripple at $500 \mathrm{rpm}$ is about $30 \%$ which is still a reduction of approximately 55\% as compared with the traditional method.

The total harmonic distortion (THD) for the current and lineline voltage for the trapezoidal and proposed method are shown in the following figures:

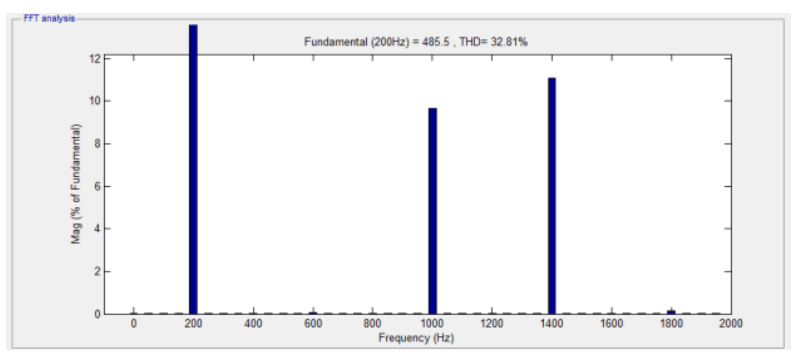

Figure.11 Line-line voltage spectrum and THD for trapezoidal control

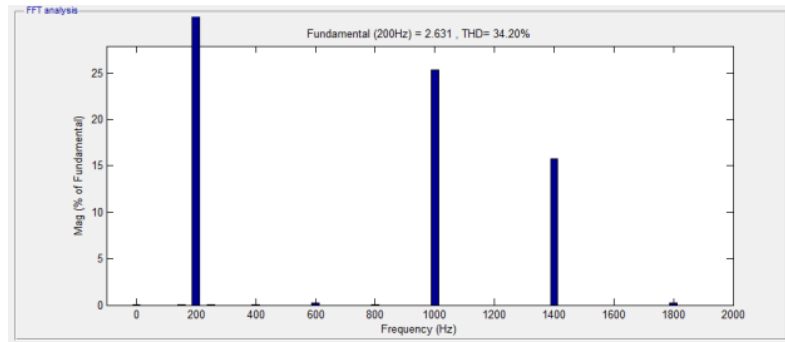

Figure.12 Current spectrum and THD for trapezoidal control 


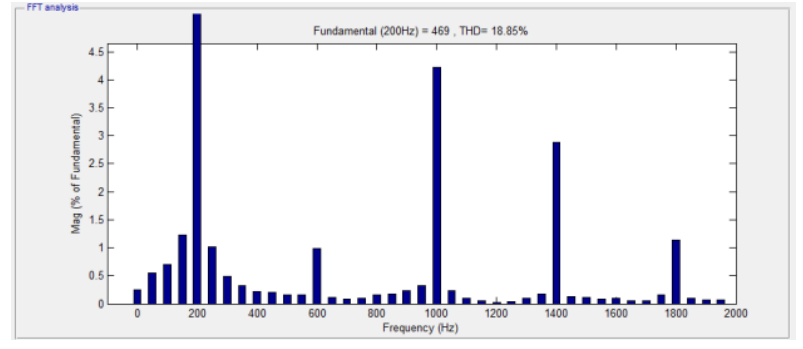

Figure 13 Line-line voltage spectrum and THD for the proposed method

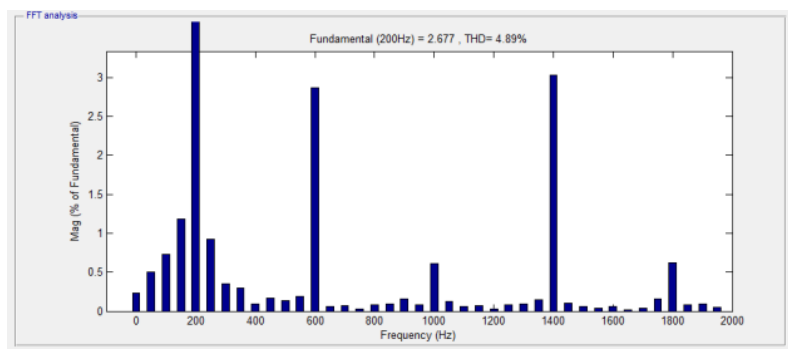

Figure 14 Current spectrum and THD for the proposed method

Figures 11-14 show the obtained THD of the current and voltage waveforms in the trapezoidal control and the proposed method. As is observed, the THD for the current and voltage waveforms in the proposed method are much less than that of the trapezoidal control.

\section{CONCLUSION AND FUTURE WORK}

In this paper, cascaded H-bridge five-level inverter with vector control are proposed to be used with BLDC motors in sensorless operation using a PLL structure.

The proposed method is compared with the traditional trapezoidal control through a number of simulations.

The simulation results obtained showed a great reduction of torque ripple as compared with the traditional trapezoidal control due to the reduction of the distortion in the voltage and current waveforms. The results also showed a good speed performance in sensorless operation for both steady and transient states.

A possible future work is to implement this method experimentally using field programmable gate array (FPGA) or microcontroller.

\section{REFERENCES}

[1] Shucheng Wang, "BLDC Ripple Torque Reduction via Modified Sinusoidal PWM", Fairchild Semiconductor Power Seminar, 2008 - 2009.

[2] Dávid Rau, Jozef Rodina, Lukáš Palkovič and Peter Hubinský,"Sensorless Field Oriented Control of BLDC Motors for MAVs", Transactions on Electrical Engineering, Vol. 4, 2015.

[3] Yousif Ismail Al Mashhadany, "High-Performance Multilevel Inverter Drive of Brushless DC Motor",
International Journal of Sustainable and Green Energy, Special Issue: Engineering Solution for High Performance of Solar Energy System. Vol. 4, No. 3-1, pp. 1-7, 2015

[4] A. Purna Chandra Rao, Y.P. Obulesh2, Ch. Sai Babu3," High Performance Cascaded Multilevel Inverter Fed Brushless DC Motor Drive", International Journal of Engineering Sciences \& Emerging Technologies, Volume 5, Issue 2, pp: 88-96 @IJESET , June 2013.

[5] A.Purna Chandra Rao,Y.P.Obulesh and CH. Sai Babu," A Five Level Cascaded Multilevel Inverter FED Brushless DC Motor With Phase Shifted Carrier PWM Techniques ", International Journal of Electrical and Electronics Engineering Research (IJEEER) ISSN 2250155X Vol. 3, Issue 1, 231-240,Mar 2013.

[6] Carlo Concari and Fabrizio Troni," Sensorless Control of BLDC Motors at Low Speed Based on Differential BEMF Measurement", IEEE, Energy Conversion Congress and Exposition, Atlanta, GA, September 2011.

[7] Taeyeon Kim, Chungil Kim and Joon Lyou," A New Sensorless Drive Scheme for a BLDC Motor Based on the Terminal Voltage Difference", IECON 2011 - 37th Annual Conference on IEEE Industrial Electronics Society, Melbourne, VIC, November 2011.

[8] Tae-Won Chun, Quang-Vinh Tran, Hong-Hee Lee, and Heung-Geun Kim," Sensorless Control of BLDC Motor Drive for an Automotive Fuel Pump Using a Hysteresis Comparator", IEEE Transactions on Power Electronics Volume 29 issue 3, March 2014.

[9] A. Purna Chandra Rao, Y. P. Obulesh and Ch. Sai Babu," Mathematical Modeling of BLDC Motor With closed Loop Speed Control Using PID Controller Under Various Loading Conditions", ARPN Journal of Engineering and Applied Sciences, VOL. 7, NO. 10, October 2012.

[10] Surin Khomfoi and Leon M. Tolbert, "Chapter 31 Multilevel Power Converters"

[11] V.Manimala, Mrs.N.Geetha M.E. and Dr.P.Renuga," Design and Simulation of Five Level Cascaded Inverter using Multilevel Sinusoidal Pulse Width Modulation Strategies", IEEE 2011 3rd International Conference on Electronics Computer Technology (ICECT) Kanyakumari, India, April 2011.

[12] Luis Carlos Giraldo Vasquez," Control of a Variable Speed Drive with a Multilevel Inverter for subsea Applications", Master thesis, Norwegian University of Science and Technology, June 2010.

[13] Sreepriya R and Ragam Rajagopal," Sensorless Control of Three Phase BLDC Motor Drive with Improved Flux Observer", International Conference on Control Communication and Computing (ICCC), 2013.

[14] Niklas Willemsen," Estimating Rotational Speed with a Phase- Locked Loop", Masters' Degree Project, Stockholm, Sweden, June 2008. 